\title{
Anti-PSMA/CD3 Monoclonal Antibody MOR209/ES414
}

National Cancer Institute

\section{Source}

National Cancer Institute. Anti-PSMA/CD3 Monoclonal Antibody MOR209/ES414. NCI

Thesaurus. Code C118626.

An anti-prostate specific membrane antigen (PSMA)/anti-CD3 bispecific humanized monoclonal antibody, with potential immunostimulatory and antineoplastic activities. Anti-PSMA/CD3 monoclonal antibody MOR209/ES414 possesses two antigenrecognition sites, one for the CD3 complex, a group of T-cell surface glycoproteins that complex with the T-cell receptor (TCR), and one for PSMA, a tumor-associated antigen (TAA) overexpressed on the surface of prostate tumor cells. Upon intravenous administration of MOR209/ES414, this bispecific antibody simultaneously binds to both CD3-expressing T-cells and PSMA-expressing cancer cells, thereby crosslinking PSMAexpressing tumor cells and cytotoxic T-lymphocytes (CT Ls). This results in CT L-mediated cancer cell lysis of prostate cancer cells expressing PSMA. 